\title{
Bupropión: una alternativa farmacológica en cesación tabáquica
}

\author{
FERNANDO DESCALZI M.*
}

Bupropion: a pharmacological alternative in smoking cessation

There are many reasons for the use of antidepressants in smoking cessation: 1) lack of nicotine can produce depressive symptoms or precipitate a severe depressive episode; 2) nicotine may have antidepressant effects that maintain addiction; 3) some antidepressants have an action on neural pathways or receptors involved in nicotine addiction; and 4) some patients do not want to use other therapies or they have failed with them. Bupropion is first-line therapy for smoking cessation, with long-term effectiveness, serious side effects are rare. The evidence suggests bupropion is similar in effectiveness to nicotine replacement therapy (NRT), and less effective than varenicline, but more studies are needed to confirm this. Bupropion is safe in psychiatric patients compensated over a period of three months or more.

Key words: Bupropion; smoking cessation; tobacco use disorder; antidepressive agents; behavior addictive.

\section{Resumen}

Hay muchas razones para el uso de antidepresivos en cesación tabáquica: 1) la falta de nicotina puede producir sintomas depresivos o precipitar un episodio depresivo grave; 2) la nicotina puede tener efectos antidepresivos que mantienen la adicción; 3) algunos antidepresivos tienen una acción en vías neuronales o receptores implicados en la adicción a la nicotina; y 4) algunos pacientes no desean usar otras terapias o han fracasado con ellas. Bupropión es terapia de primera línea para la cesación del tabaco, con efectividad a largo plazo, los efectos adversos graves son escasos. La evidencia sugiere que bupropión es de eficacia similar a la terapia de reemplazo de nicotina (TRN) y menos eficaz que vareniclina, pero se necesita más estudios para confirmar esto. Bupropión es seguro en pacientes psiquiátricos compensados en un periodo de tres meses o más.

Palabras clave: Bupropión; dejar de fumar; tabaquismo; agentes antidepresivos; comportamiento adictivo.

Existen varios motivos por los que debe considerarse el uso de antidepresivos en cesación tabáquica: Primero, la falta de nicotina puede producir síntomas depresivos o precipitar un episodio depresivo grave; segundo, la nicotina puede tener efectos antidepresivos que mantienen esta adicción; tercero, algunos antidepresivos tienen una acción en vías neuronales o receptores que participan en la adicción a la nicotina y cuarto, algunos pacientes no desean usar otras terapias o han fracasado con ellas.

De los antidepresivos, el más usado para dejar de fumar es bupropión, este medicamento tiene acciones dopaminérgicas y adrenérgicas y parece ser antagonista del receptor nicotínico acetilcolinérgico.

Cochrane Library ha publicado recientemente evidencia de gran calidad, que apoya el uso de bupropión como ayuda para dejar de fumar a largo plazo $^{1}$. Hubo evidencia de alta calidad que, cuando se usó como la única farmacoterapia, el bupropión aumentó significativamente el cese a largo plazo. Se revisaron 44 ensayos, que incluyen a 13.728 pacientes, que usaron como única

* Dpto. Enfermedades Respiratorias, Programa Tabaquismo, Clínica Alemana de Santiago, Chile. 
terapia farmacológica el bupropión, durante tres meses, obteniendo un RR de 1,62 (95\% CI 1,491,76) de cesación tabáquica exitosa a 6 meses Basándose en una cantidad limitada de datos de comparaciones directas, el bupropión y nortriptilina parecen ser igualmente eficaces y de eficacia similar a la TRN (bupropión versus nortriptilina 3 ensayos, $\mathrm{n}=417$, RR 1,30, IC del 95\%: 0,93 a 1,82, bupropión frente a NRT $8 \mathrm{n}=4.096$, RR 0,96, IC del 95\%: 0,85 a 1,09, sin comparación directa entre nortriptilina y NRT). Los resultados combinados de cuatro ensayos que compararon bupropión con vareniclina mostraron un abandono significativamente más bajo con bupropión que con vareniclina $(\mathrm{n}=1810, \mathrm{RR} 0,68, \mathrm{IC}$ del 95\%: 0,56 a 0,83 ).

Los efectos adversos más comunes del bupropión son insomnio que ocurre entre el $30 \%$ a $40 \%$ de los pacientes, en menos de un 5\% boca seca, cefaleas y temblor. También se han reportado reacciones alérgicas angioedema $(0,1 \%)$. En cuanto a efectos adversos severos, un meta-análisis de (33 ensayos, $\mathrm{n}=9.631$, RR 1,30, IC del 95\%: 1,00 a 1,69) no detecta un aumento significativo de estos en relación a placebo. En el análisis de subgrupo de efectos adversos psiquiátricos tampoco se observaron diferencias entre bupropión y placebo. Se ha reportado un riesgo de 1 en 1.000 de presentar convulsiones, por lo que una contraindicación a su uso es el antecedente de epilepsia. La tasa de suspensión del bupropión por efectos adversos en los diferentes estudios va desde $7 \%$ a $31 \%$.

En cuanto a la dosis en 3 estudios se ha comparado 150 vs $300 \mathrm{mg}$, no encontrándose diferencias significativas en abstinencia con RR de 1,08 (IC 95\% 0,83-1,26). La dosis habitual es de 150 $\mathrm{mg}$ al día durante los 3 primeros días y luego se sigue con $150 \mathrm{mg}$ cada 12 por 7 a 12 semanas.

No obstante, la evidencia anterior, aun no se había respondido plenamente la pregunta sobre la eficacia comparada e incidencia de efectos adversos psiquiátricos de vareniclina, bupropión y terapia de reemplazo de nicotina en población normal y con historia psiquiátrica.

Se realizó un estudio doble ciego, randomizado contra placebo ${ }^{2}$, en 140 centros y 16 países, entre ellos Chile, con 8.144 participantes (4.116 participantes en cohorte psiquiátrica, compensados por tres meses, y 4.028 en cohorte no psiquiátrica). Aproximadamente 1.000 participantes de cada grupo se randomizó a vareniclina $(1 \mathrm{mg}$ por dos veces al día), bupropión (150 mg por dos veces al día), parches de nicotina (21 $\mathrm{mg}$ con reducción posterior) y placebo.

En la cohorte no psiquiátrica se reportó 1,3\% de efectos adversos neuropsiquiátricos con vareniclina, 2,2\% con bupropión, 2,5\% con parche de nicotina y $2,4 \%$ con placebo. Las diferencias de riesgo de estos efectos para bupropión versus placebo son de - 0,08 (-1,37-1,21). En la cohorte psiquiátrica un $6,5 \%$ reportó efectos adversos neuropsiquiátricos con vareniclina, $6,7 \%$ con bupropión, $5,2 \%$ con parche de nicotina y $4,9 \%$ con placebo. La diferencia de riesgo para bupropiónplacebo es de 1,52 (IC 95\% 0,24-3,59). En esta cohorte casi la mitad de los participantes estaban con terapia psiquiátrica farmacológica compensados por tres meses.

Las tasas de abstinencia (semanas 9-12) fueron mejores con vareniclina que bupropión con OR de $1,75(1,52-2,01)$ y bupropión es mejor que placebo con OR de 2,07 (1,75-2,45). Si se compara eficacia de bupropión con otros fármacos en cohorte no psiquiátrica versus psiquiátrica, las tasas de abstinencia de vareniclina versus bupropión es de OR 1,77 y de 1,74 respectivamente y de bupropión vs placebo es de OR 2,26 y 1,87 respectivamente.

El estudio no mostró un aumento significativo en los eventos neuropsiquiátricos adversos atribuibles a vareniclina o bupropión en relación con el parche de nicotina o el placebo. La vareniclina fue más eficaz que el placebo, la nicotina parche y bupropión para ayudar a los fumadores a lograr la abstinencia, mientras que el bupropión y el parche de nicotina fueron más eficaces que el placebo

\section{Farmacoterapia}

Efectos secundarios: el más común: insomnio $(30-40 \%)$ y en $<5 \%$ se reportan cefaleas, boca seca, temblor. Entre los efectos serios se describe, angioedema $(0,1 \%)$, convulsiones $(1 / 1.000)$.

Contraindicaciones: pacientes con antecedentes de convulsiones, tumores del sistema nervioso central, bulimia, anorexia o trastorno bipolar. Uso junto a inhibidores de la MAO. No se recomienda administrarlo en el embarazo ni en lactancia.

Asociación de fármacos: puede ser usado en conjunto con inhibidores recaptación serotonina (citalopram-escitalopram, fluoxetina, paroxetina, sertralina) y asociado a TRN.

Prescripción: inicio una semana antes del prefijado "Día D (primer día sin fumar ) iniciar con $150 \mathrm{mg}$ en la mañana por 3 días, luego 150 x 2 veces, última dosis a las $15-16 \mathrm{~h}$ o antes, para minimizar insomnio. En adultos mayores se recomienda reducir dosis a $150 \mathrm{mg}$ al día, también se puede reducir dosis en pacientes con 
mala tolerancia al fármaco, los pacientes con depresión o trastornos de ansiedad se podrían beneficiar más con bupropión que con otros medicamentos.

Finalmente bupropión es terapia de primera línea para la cesación del tabaco, ayuda a la cesación del tabaco a largo plazo, los efectos adversos graves son escasos como para suspender el fármaco. La evidencia sugiere que bupropión es de eficacia similar a TRN y menos eficaz que la vareniclina, pero se necesitan más investigaciones para confirmar este hallazgo. Bupropión es seguro en pacientes psiquiátricos compensados por tres meses.

\section{Bibliografía}

1.- Antidepressants for smoking cessation .Hughes JR, Stead LF, Hartmann -Boyce J, Cahill K, Lancaster T. Cochrane Database of Systematic reviews 2014, Issue 1.

2.- ANTHENELLI RM, BENOWITZ NL, WEST R, ST AUBIN L, MCRAE T, LAWRENCE D, et al. Neuropsychiatric safety and efficacy of varenicline, bupropion, and nicotine patch in smokers with and without psychiatric disorders (EAGLES) : a double-blind, randomised, placebo-controlled clinical trial. Lancet. 2016 Jun 18;387(10037):2507-20. doi: 10.1016/S01406736(16)30272-0. 